\title{
Influence of the Amount of Master Alloy on the Properties of Austenitic Stainless Steel AISI 316L Powder Sintered in Hydrogen
}

\author{
Mateusz Skałoń ${ }^{1}$, Jan Kazior ${ }^{1}$ \\ ${ }^{1}$ Cracow University of Technology, Mechanical Department, Warszawska Street 24, 31-155 Cracow, Poland \\ Correspondence to: kazior@mech.pk.edu.pl
}

\begin{abstract}
AISI 316L austenitic stainless steel powder was modified with four different amounts of boron (0.1;0.2;0.3;0.4 of wt. \%) in the form of MasterAlloy micro-powder, and was sintered in a pure dry hydrogen atmosphere in order to obtain high density sintered samples characterized by a thickened non-porous surface layer. We investigated the influence of the amount of boron on: density, hardness, grain microhardness, porosity, microstructure and surface quality. The study revealed that it is possible by a conventional compacting and sintering process to obtain near full-density sintered samples with a non-porous superficial layer without boride precipitations.
\end{abstract}

Keywords: master alloy, stainless steel, sintering.

\section{Introduction}

Sintered austenitic stainless steel powders (e.g. AISI 316L) cause some serious problems connected especially with the presence of open porosity. This allows an aggressive fluid to penetrate the bulk material, which remarkably intensifies the corrosion rate. In order to extend the applications of sintered stainless steels, increased density and decreased total porosity, in particular open porosity, are necessary. It has beenfound that when ferrous metals powders are sintered with the addition of boron powder, a nonporous surface layer is formed [1-11]. Unfortunately, high addition of elemental boron stimulates the appearance of a eutectic liquid phase during sintering, which in fact intensifies the processes of mass transport phenomena, while at the same time creating an almost continuous network of borides surrounding the matrix grains. This significantly decreases the mechanical properties of the sintered material. The main goal of our investigation was to obtain a high-density sintered material with a non-porous superficial layer without boride precipitations.

\section{Experimental precedure}

Cylindrical specimens $5 \mathrm{~mm}$ in length and $20 \mathrm{~mm}$ in diameter of AISI 316L austenitic stainless steel powders modified with five different amounts of boron containing Master Alloy micro-powder (0.1; $0.2 ; 0.3$; 0.4 of wt. $\%$ ), were uniaxially compacted at $600 \mathrm{MPa}$. Only the punch and die walls were lubricated with zinc stearate in order to avoid contamination of the mixtures of powders. The sintering process was per- formed in a tubular furnace in a pure dry hydrogen atmosphere according to the temperature profile presented below:

- heating from room temperature up to $1240^{\circ} \mathrm{C}$, with a heating rate of $10^{\circ} \mathrm{C} / \mathrm{min}$.

- isothermal sintering at a temperature of $1240{ }^{\circ} \mathrm{C}$ for $30 \mathrm{~min}$,

- cooling to $30^{\circ} \mathrm{C}$ with a cooling rate of $20^{\circ} \mathrm{C} / \mathrm{min}$,

- temperature stabilization to $30^{\circ} \mathrm{C}$ for $60 \mathrm{~min}$.

Density was measured by the water displacement method according to the PN-EN ISO 2738:2001 standard.

Hardness tests were carried out using the Vickers hardness tester. Ten measurements were taken, and the results were calculated as an average value. The standard deviation calculation was also based on this data.

Specimens for the microstructures were obtained by means of a particular procedure aimed at avoiding modifying the porosity morphology. Microstructures were revealed by etching in Villel's etchant for stainless steels at a temperature of $80^{\circ} \mathrm{C}$. The porosity was determined by digital image analysis as a function of the boron content.

The microhardness of the grains was measured after etching: ten measurements were performed for each sample. $10 \mathrm{~g}$ was used as a test load. The load acting time was 10 seconds.

Porosity analysis was performed using Aphelion $^{\mathrm{TM}}$ software.

A surface quality check was carried out by observing a cross-section of the sample using an optical microscope. 


\section{Results and discussion}

\subsection{Density}

Figure 1 presents the influence of the amounts boron on the sintered density of AISI 316L powders. It is clear that the sintered density increased with an increasing amount of boron, and in particular when the amount of boron exceeded $0.3 \%$ wt. The major increase in sintered density for $0.3 \%$ wt. amount of boron suggests some changes in the sintering mechanisms than when smaller lower amounts of boron were added.

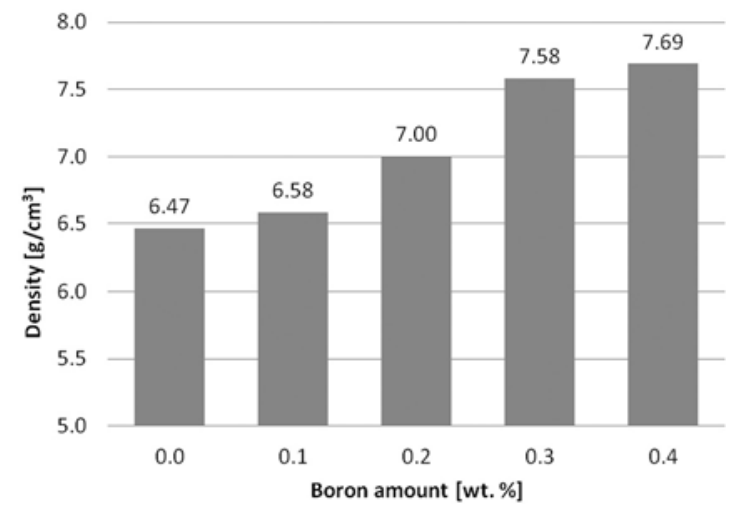

Figure 1: Influence of the amount of boron on the sintered density of AISI 316L powders

\subsection{Hardness}

Figure 2 and Table 1 present the results of Vickers HV 10 hardness measurements of sintered AISI 316L powders. Similarly as in the case of density, an increase in the amount of boron increases the hardness of the sintered materials. In particular in the case of the addition of $0,4 \mathrm{wt} . \%$ boron, the hardness is 2.5 times higher than hardness of the base material. This is directly connected with the increase in density.

\subsection{Microhardness}

Figure 3 presents the results of microhardness measurements of sintered AISI 316L powders.

Unlike in the case of density and hardness, the grain microhardness measurements indicate that the addition of boron does not influence the grain microhardness.

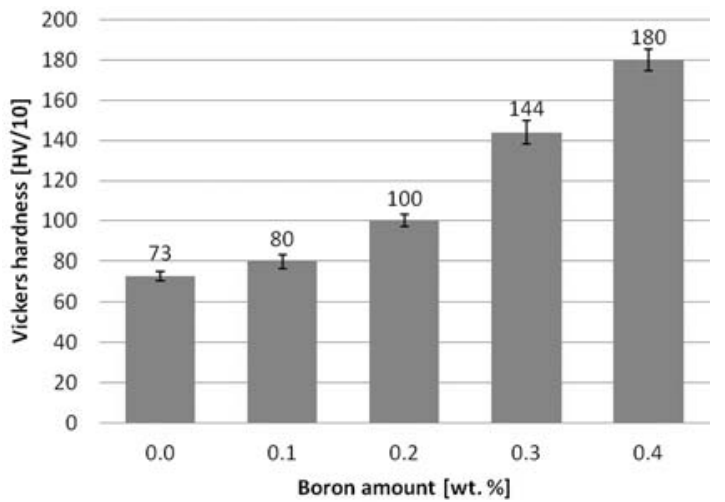

Figure 2: Influence of the amount of boron on the Vickers hardness of sintered AISI 316L powders

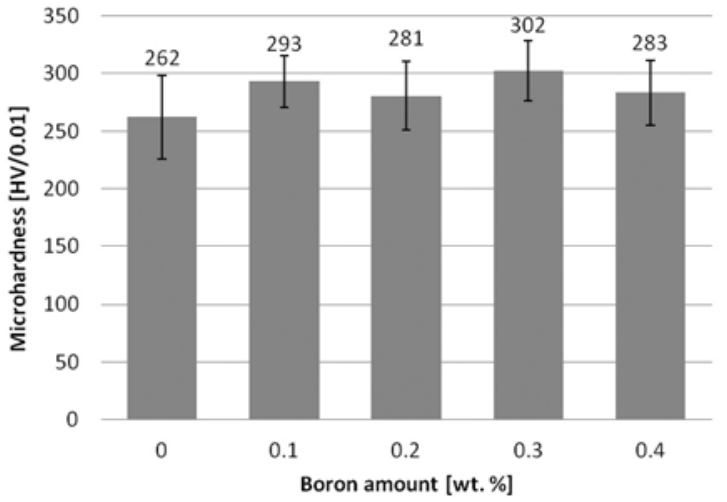

Figure 3: Influence of the amount of boron on the microhardness of sintered AISI 316L powders

Table 1: Hardness data

\begin{tabular}{|l|c|c|c|c|c|}
\hline Boron amount [wt. \%] & 0.0 & 0.1 & 0.2 & 0.3 & 0.4 \\
\hline $\mathbf{H V} / \mathbf{1 0}$ & 73 & 80 & 100 & 144 & 180 \\
\hline Standard deviation & \pm 1.1 & \pm 1.3 & \pm 1.6 & \pm 4.6 & \pm 3.9 \\
\hline
\end{tabular}

Table 2: Microhardness data

\begin{tabular}{|l|c|c|c|c|c|}
\hline Boron amount [wt. \%] & 0.0 & 0.1 & 0.2 & 0.3 & 0.4 \\
\hline HV/0.01 & 262 & 293 & 281 & 302 & 283 \\
\hline Standard deviation & \pm 36.0 & \pm 22.3 & \pm 29.9 & \pm 26.2 & \pm 28.1 \\
\hline
\end{tabular}




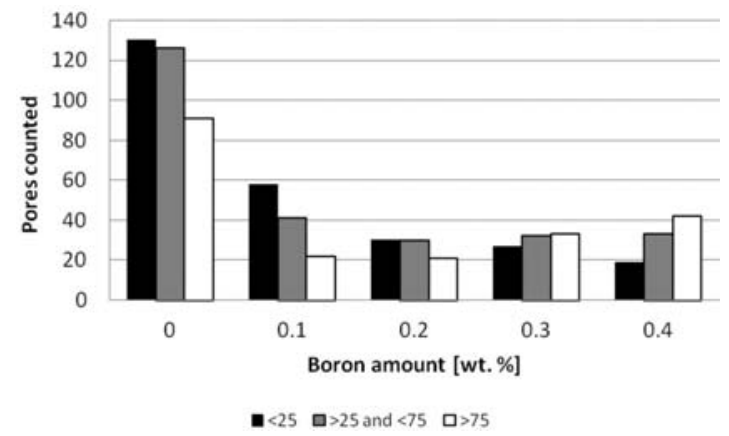

Figure 4: Influence of the amount of boron on the pore area in three different ranges $<25 \mu \mathrm{m}^{2}$, $25-75 \mu \mathrm{m}^{2}$ and $>75 \mu \mathrm{m}^{2}$

The boron alloyed-samples had only slightly higher microhardness than the base sintered material. This is due to some diffusion of the alloying elements from Master alloy powder to the austenitic matrix This means that the increase in Vickers hardness is a consequence of increased density, but that the microstructure does not change.

\section{Pore Morphology}

Figure 4 presents pores as a function of boron content. It may be noted that with increasing boron content the pore area changed. For the boron-free samples, a small area of pores dominated, while for a higher amount of boron a larger area of pores dominates. The results presented in Figure 4 show that the trend changes at $0.3 \%$ wt. boron addition. This behavior is well connected with the development of density: with $0.3 \%$ wt. addition of boron considerable growth in density was also observed.

This behavior is well related with phenomena associated with liquid-phase sintering when microstructural coarsening occurs in the final stage of sintering. Along with grain growth there are simultaneous changes in pore size, inter-granular neck size, grainliquid interfacial area and mean grain separation.

\section{$5 \quad$ Microstructures}

Figure 5a presents the microstructure of boron-free sintered austenitic stainless steel, and Figure $5 \mathrm{~b}$ presents the microstructure of $0.4 \%$ wt. boron alloyed AISI316L.

In principle, the microstructure is characterized by two different layers. The first is the dense superficial layer (Figure 7) which after appearing of the precipitations develops into second one: layer rich in borides but characterized with much lower porosity than sample's core (Figure 6). The network of borides surrounding the austenitic grains is caused by the solidification of the liquid phase that forms at high temperature through an eutectic reaction. The network is constituted by complex Cr-Mo-Fe borides [4].
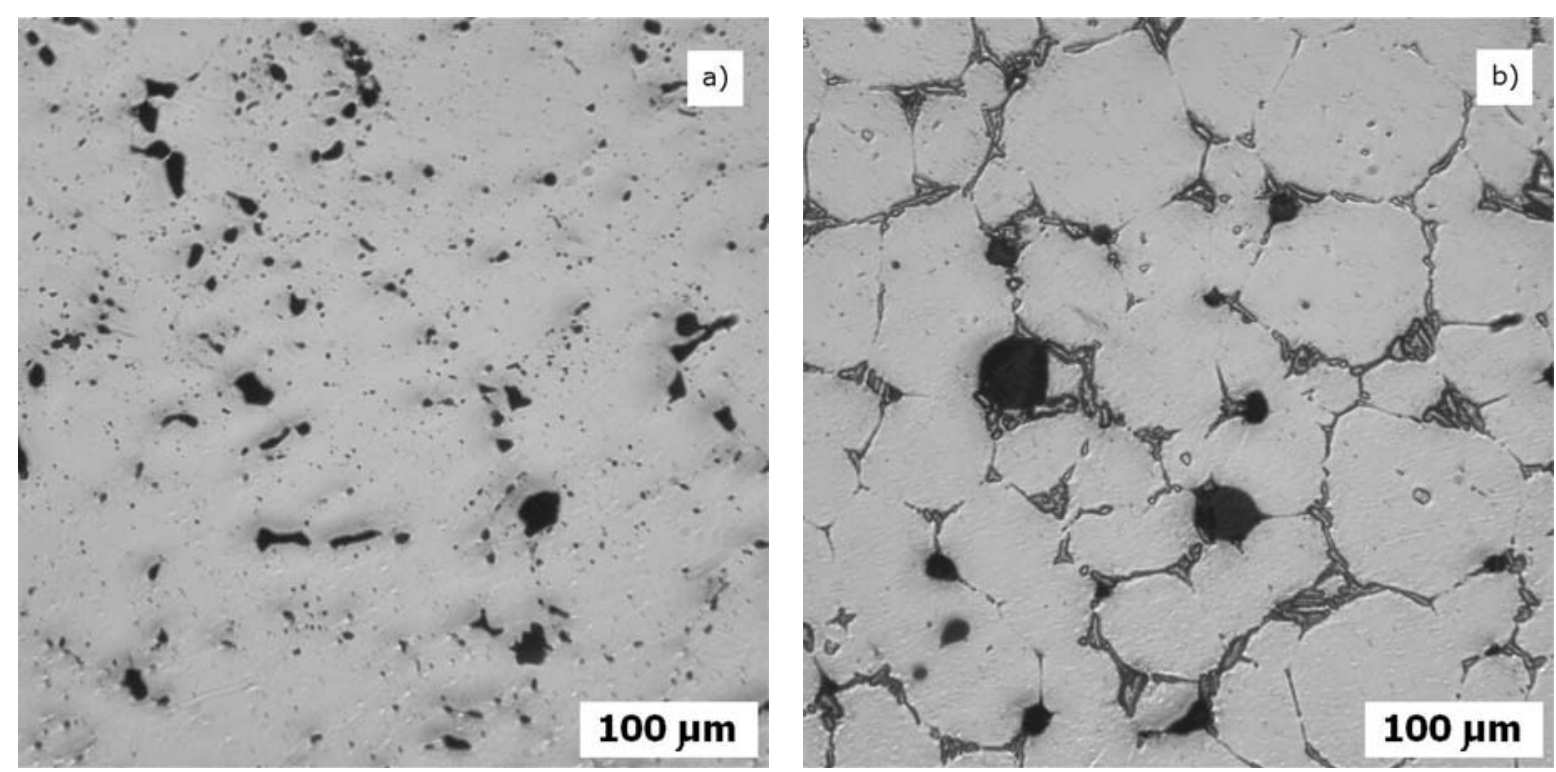

Figure 5: Porosity of a) sintered AISI 316L base powder and b) AISI 316L modified with 0.4 wt. \% of boron in MasterAlloy form 

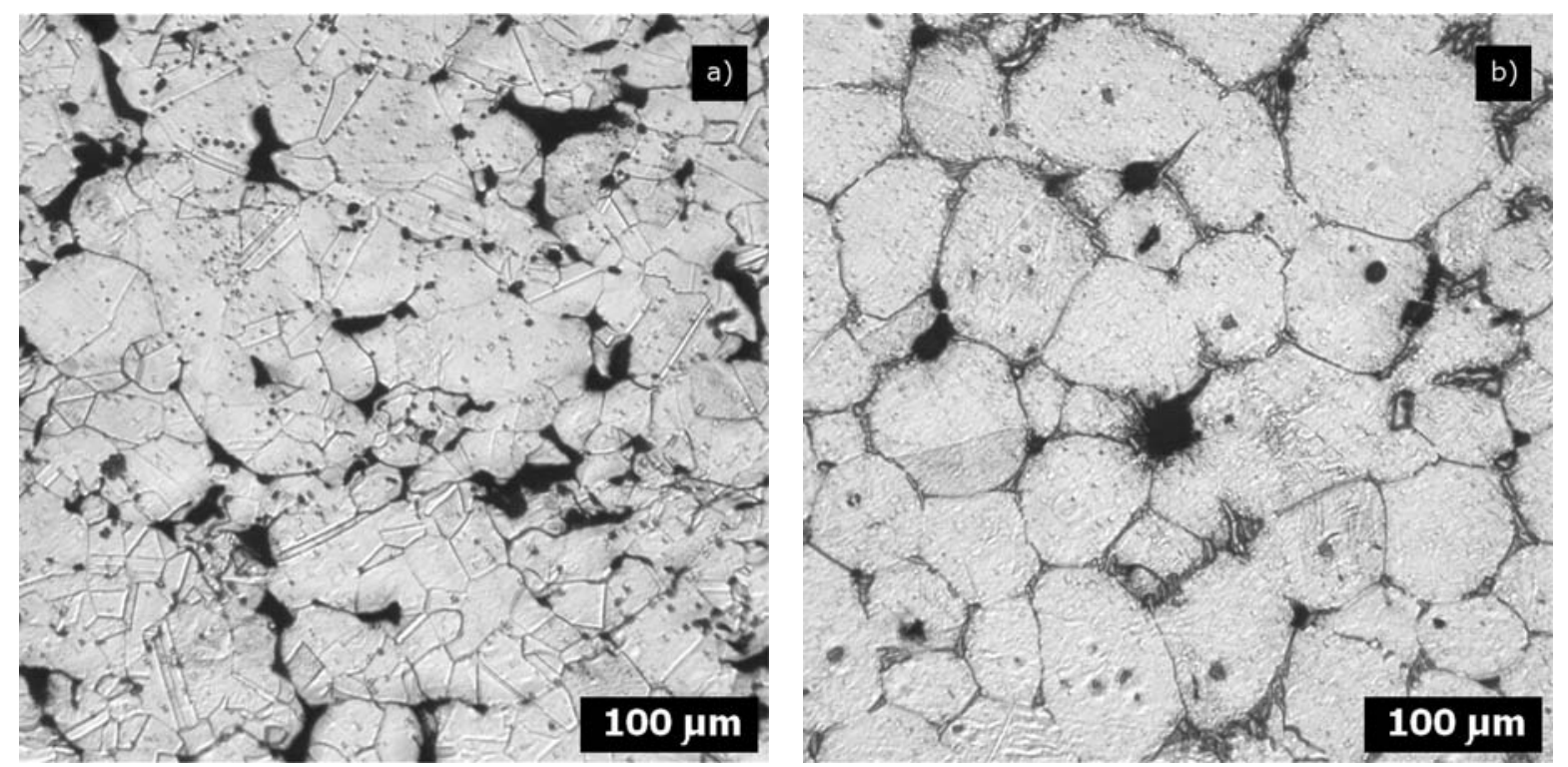

Figure 6: Core microstructure of a) sintered AISI 316L base powder and b) AISI 316L modified with 0.4 wt. $\%$ of boron in MasterAlloy form
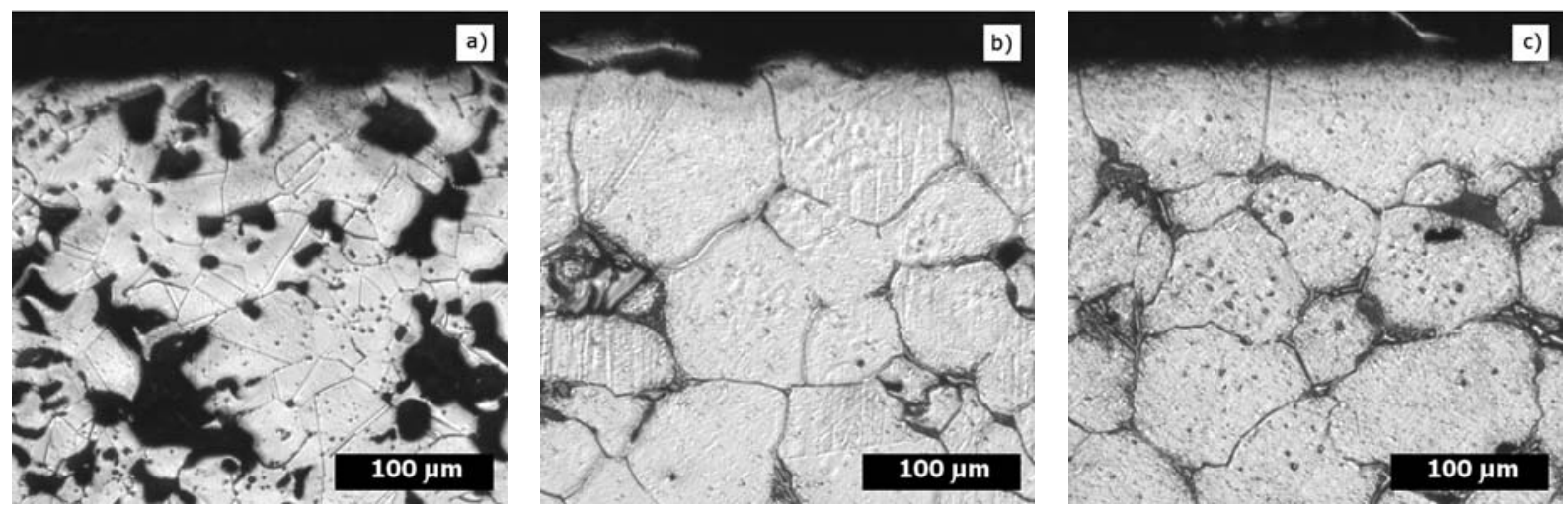

Figure 7: Surface microstructure of a) sintered AISI 316L base powder and b) AISI 316L modified with 0.3 wt. $\%$ of boron in MasterAlloy form c) AISI 316L modified with 0.4 wt. \% of boron in MasterAlloy form

In addition, the evolution of a boride network suggests that the surface layer is formed by a pore filling mechanism described theoretically by Lee S. M and Kang S. J. [11]. When the grain growth process occurs, there is a pressure imbalance between the outer surface of the specimen and the inner surface of the pores, which pushes the liquid into the internal pores. Increasing in grain size, the radius of the external meniscus decreases, causing an increase in the external pressure with respect to the internal pressure. As a consequence of this pressure imbalance, the liquid is induced to flow into the internal pores of the sample. This phenomenon therefore produces penetration of the liquid towards the inner part of the sample, and the concomitant formation of a liquid-free layer on the surface, where the pores have almost completely disappeared. The penetration of the liquid enriches the intermediate layer, and the liquid tends to flow towards the bulk. When the boron content increases, the amount of the liquid phase increases overall in the samples, and this influences the pore-filling mechanism.

\section{Surface quality}

In the case of 0.3 wt. $\%$ and 0.4 wt. $\%$ of added boron, a non-porous and boride-free superficial layer was obtained. The microhardness of the superficial layer is similar to the microhardness of the sample core. The thickness of the superficial layer varies between $40 \mu \mathrm{m}$ and $100 \mu \mathrm{m}$. In addition, there is a noticeable improvement in surface quality for the boron alloyed specimens, in particular for 0.3 and 0.4 wt $\%$ when compared with the surface microstructure of the base material. 


\section{Conclusion}

Introducing a high amount (0.3 wt. \% and 0.4 wt. \%) of boron in the form of MasterAlloy into austenitic stainless steel powders causes: increased sintered density and, as a consequence, increased hardness of sintered austenitic stainless steels. However, it should be pointed out that the introduction of boron in the form of Masteralloy enabled the formation of a non-porous and plain surface, with no precipitations. This led to an improvement in corrosion resistance.

However, further investigations should focus on obtaining a non-porous layer that is at the same time free of grain boride network bulk material.

\section{Acknowledgement}

This research was supported by the Polish Ministry of Science and Higher Education, grant no N 508479138 .

\section{References}

[1] Klar, E., Samal, P.: Powder Metallurgy Stainless Steel. Ed. ASM, 2007.

[2] Tandon, R., German, R. M.: The international Journal of Powder Metallurgy, Vol. 34, No. 1, 1998, p. 40-49.
[3] Molinari, A., Kazior, J., Marchetti, F., Cantieri, R., Cristofolini, A., Tiziani, A.: Powder Metallurgy 1994, Vol. 37, No. 2, p. 115-122.

[4] Molinari, A., Straffelini, G., Pieczonka, T., Kazior, J.: The International Journal of Powder Metallurgy, 1998, Vol. 34, No. 2, p. 21-28.

[5] Velasco, F., et al.: Material Science and Technology, 1997, Vol. 13, p. 847-851.

[6] Toennes, C., Ernst, P., Meyer, G., German, R. M.: Advances in Powder Metallurgy, 1992, Vol. 3, p. 371-381.

[7] Menapace, C., Molinari, A., Kazior, J., Pieczonka, T.: Powder Metallurgy, 2007, Vol. 50, No. 4, p. 326-335.

[8] Sarasola, M., Gomez-Acebo, T., Castro, F.: Powder Metallurgy, 2005, Vol. 48, No. 1, p. 59-67.

[9] Selecka, M., Salak, A., Danninger, H., J. Mat. Proc. Techn, 2003, Vol. 143, p. 910-915.

[10] Selecka, M., Danninger, H., Bures, R., Parilak, L.: Proc. PM World Cong. 1998, Granada, Spain, October 1998, EPMA, Vol. 2, p. 638-643.

[11] Lee, S. M., Kang, S. J.: Acta Materiala, 1998, Vol. 46, No. 9, p. 3191-3202. 